\title{
Translating new knowledge into practical and effective tools for geotechnical risk and database management in deep high stress mines
}

\author{
DJ Duff Centre for Excellence in Mining Innovation, Canada
}

\begin{abstract}
Since its inception the Centre for Excellence in Mining Innovation (CEMI) has worked closely with the mining industry to identify the challenges it faces in making deep mines safer and less risky. Efforts have focused on identifying knowledge and technology gaps in design and performance-related activities and on devising improvements aimed at addressing them. This paper will provide an overview of the progress to date some five years after initiation of this effort. Tools and guidelines already made available to the industry through CEMI will be reviewed, and new ones currently being prepared will be highlighted. As well, state of the art rock mass monitoring research will be summarised as will results to date of a cross-disciplinary (mining and oil and gas industry) set of field trials being conducted by CEMI in Australia where fluid injection is being investigated as a means to re-distribute stress at a block scale in deep underground mines. This work, if successful, will mean that new tools and new approaches may be required for dealing with stress management in deep mines elsewhere, including in Canada. Finally, a new approach being led by CEMI to building database collection, integration and management capability within our industry will be highlighted.
\end{abstract}

\section{$1 \quad$ Introduction}

CEMI's DeepMine research theme has focused since its inception in 2007 on finding ways to identify, mitigate and manage the geotechnical risks associated with deep mining. This work has received broad industry support from around the world largely because geotechnical risk, in particular as it relates to the health and safety of our employees as well as the investment risks posed as we go deeper, is agreed by all to be substantial.

In order to provide value for industry and to help enable deeper, and, if possible, more intensive mining, CEMI's DeepMine research and development theme has followed a two-pronged approach with one focused on keeping the scoreboard ticking over for industry by producing tools and guidelines periodically which help address nearer term, more immediate concerns, and the other focused on addressing perhaps the more perplexing issues, that is those related to monitoring and even modifying rock mass behaviour in response to mining over the longer term. These latter challenges are fundamental to assessing the reliability of our deep mine excavations as well as our production expectations over time. They also are critical to understand when designing underground deep mines.

2

$$
\text { Methodology }
$$

\section{$2.1 \quad$ Tools and guidelines}

Several tools and guidelines have already been produced for industry by CEMI and will not be reported on again here. They include: GeoHazMap (Mira Geoscience 2013), BurstSupport Tool Phase I (MIRARCO 2013) and S-GMAT Tool (International Mine Seismology Group 2013). The reader is referred to Duff et al. (2011) and other papers referenced therein for a fuller description.

Nevertheless, work continues in these areas and, more recently, select ongoing related projects with potential significant value for industry include the following. 


\subsubsection{Burst support tool - Phase II (MIRARCO and Laurentian University)}

Although Phase I of this software tool, including an updated version of the 'Canadian Rockburst Research Handbook', last produced in 1996, is highly valuable to rock engineers when dealing with ground support selection, particularly in dynamic loading situations, ongoing research, coupled with feedback received from industry sponsors, has suggested the further need to better understand:

- Why rockburst damage varies in the areas close to the seismic source?

- Why installed rock support failed at some locations?

- What is the major mechanism of rockburst damage?

A three year programme of research involving case studies at several underground mine sites has just been initiated to address this.

Assessment of damage records, including geology and structure, coupled with an assessment of ground support components being used at the point of failure, will be conducted and examined forensically to determine causality and possible remedies (Figure 1). BurstSupport Tool in conjunction with the S-GMAT tool (Figure 1) will be used simultaneously to optimise the investigation by comparing ground support performance with modelled ground motions.

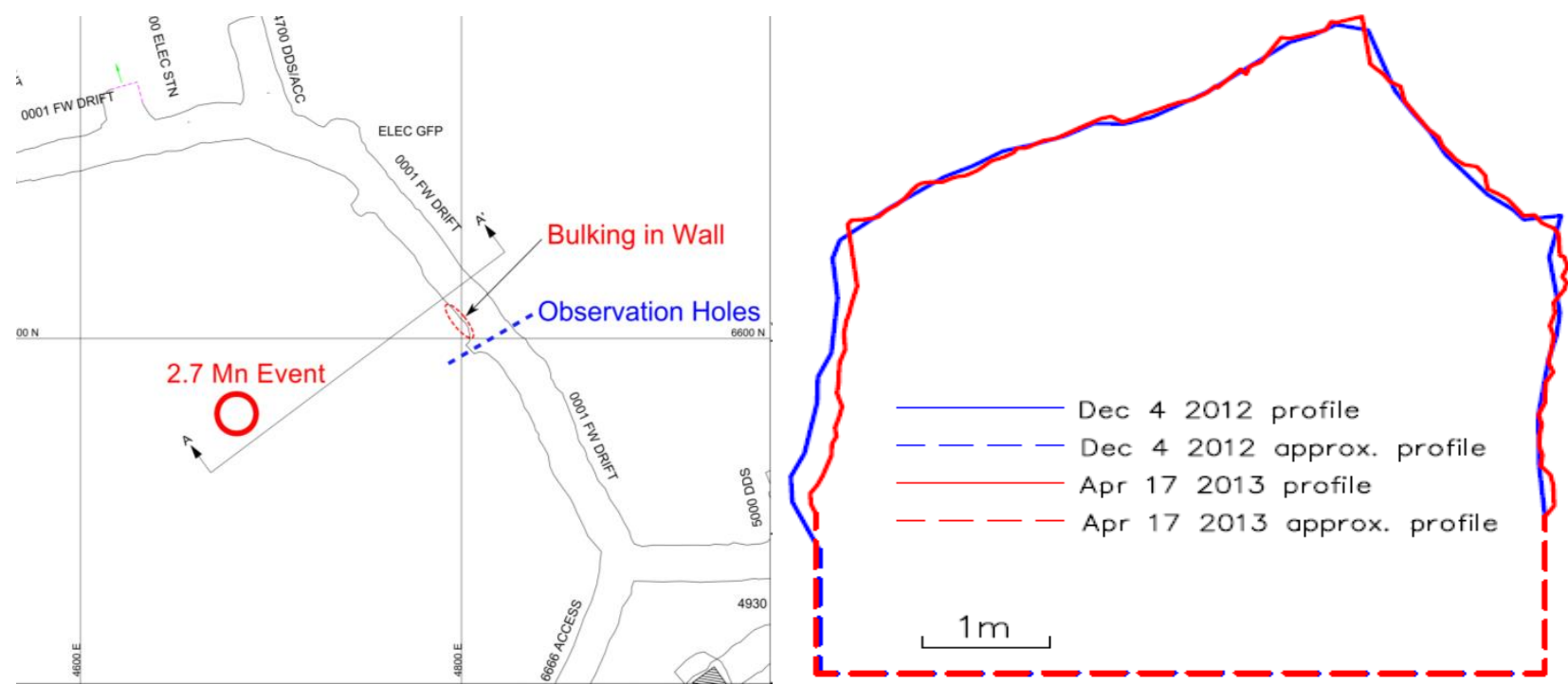

Figure 1 Case study location at Creighton Mine in Sudbury (Groccia et al. 2014)

In parallel, it has also been suggested that there is need to investigate the matter of ground failure or strainbursting produced when stored energy in excavation walls is released suddenly during mining rather than perhaps in direct response to a known seismic event - often the more commonly assumed causal factor. Kaiser \& Cai (2013a, b) suggests that the current ground motion centric design approach; $(E=f(p p v)) . .$.$) essentially ignores the limited pool of energy stored near excavation boundaries and released$ during seismically triggered strainbursts. In this case, damage is primarily related to the state of stress as well as the local mine stiffness at the potential damage location and not, or only indirectly related, to the seismic ground motions (Figure 2). 

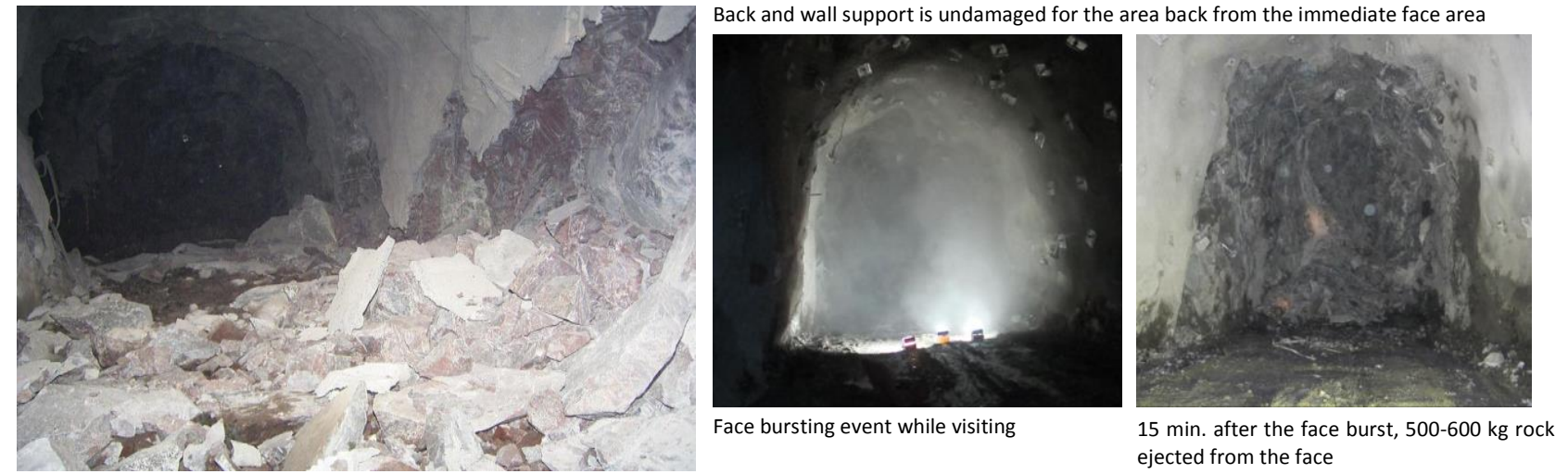

\section{Figure 2 Damage extent not always relatable to ground motions (after Kaiser 2013b)}

Therefore, according to Kaiser (2013b) the vulnerability of excavations has three components:

- How close to failure the rock mass is?

- Glass full or half full.

- How brittle the rock is?

- Role of confinement and support to change rock brittleness/stiffness.

- What is the primary energy source?

- How much deformation potential?

○ Damage is a function of energy stored in loading system.

He concludes that the ground motions can often be the trigger and not necessarily the cause of damage. He further adds that more work is needed focused on concept verification by numerical modelling and, ideally, should include strainburst case studies focused on methods to assess deformation potential and related deformation based ground support rationale.

\subsubsection{GeoRisk Manual (Queen's University, CEMI and ETH)}

As previously reported in Duff et al. (2011), the 'GeoRisk Manual' - then in preparation - emphasised the importance of the specific components of a proper geotechnical mine design model, namely that it is comprised of an assessment of hazards that may originate with: the design model (whether empirical or numerical), the geotechnical model (comprised of rock mass and other characterisation data) and the behaviour/failure model (Figure 3).

It further underscored the need for a confidence-based approach which recognises the need to build assurance in our assessments through data collection and analysis before advancing. 


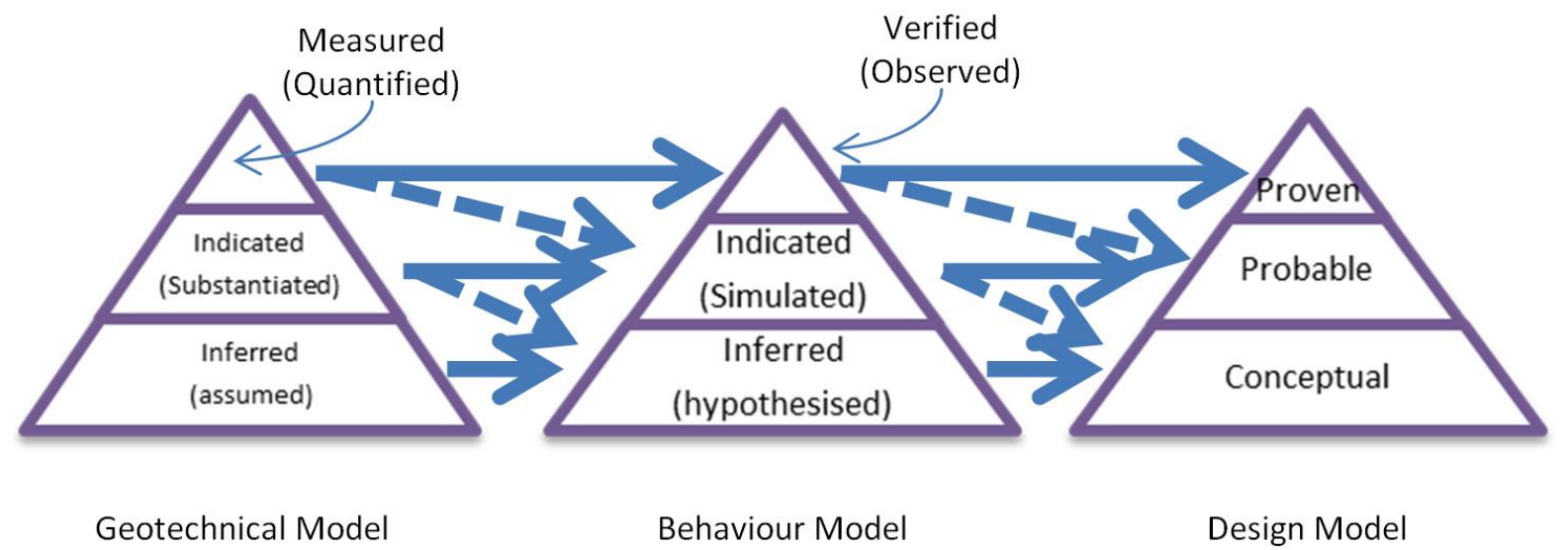

Figure 3 Arrows indicating the possible confidence level evolution paths when considering geotechnical risk for a mining project (Kaiser et al. 2014)

Ongoing CEMI-sponsored work in this area, primarily led by Dr. Connor Langford and Dr. Mark Diederichs at Queen's University, has re-focused the work somewhat and emphasises the need to better define:

- Uncertainty in intact and rock mass parameters such as:

- Key intact parameters and performance indicators (design outputs) for various failure mechanisms.

- Uncertainty in stress conditions and, among other things:

- A review of the integrated stress approach and how it can be used to assess uncertainty in stress conditions.

- Reliability methods:

- The review of discrete (FOSM, PEM, FORM, RSM) and random sampling (Monte Carlo) approaches.

And finally, to develop:

- A quantitative risk approach which:

- Further discusses the Pyramid approach presented above;

- understands the consequence of failure with respect to underground support elements;

$\circ$ helps to determine what is acceptable risk?

Work on this revised 'GeoRisk Manual' is scheduled for completion before the end of 2014 (Kaiser, Langford \& Diederichs, pers. comm.) and will be available for general distribution thereafter.

\subsubsection{Discrete fracture network modelling-MoFrac (MIRARCO, Laurentian University and Benchmark 6))}

Understanding the distribution of fractures in a rock mass is fundamental to determining the likely response of that rock mass to imposed stresses. Existing methods rely heavily upon direct observations coupled with supplementary modelling approaches which use discrete fracture network (DFN) modelling tools.

CEMI, working closely with the Nuclear Waste Management Organization (NWMO) and with Benchmark 6 has contracted MIRARCO to further enhance and upgrade a DFN tool first developed by Benchmark 6 many years ago. 
In its newly developed state, the tool would ensure greater value for both the mining industry as well as the nuclear waste management world by providing improvements over other DFN tools in how fracture undulations are handled, how known geological structures are dealt with, including how:

1. They are clustered or domained.

2. Different (more attribute-style or user defined) data are incorporated.

3. How intersections between fracture sets are handled.

These, it is thought, will lead to a greater degree of visual realism and thereby also make for a very good communication tool for use in geomechanical and flow modelling applications.

Research to be conducted at the same time as the DFN tool upgrade will address how additional functionality can be added while also looking at how this may be used to enhance mine design - thereby potentially making mines safer with a more reliable anticipated production performance (Figure 4).

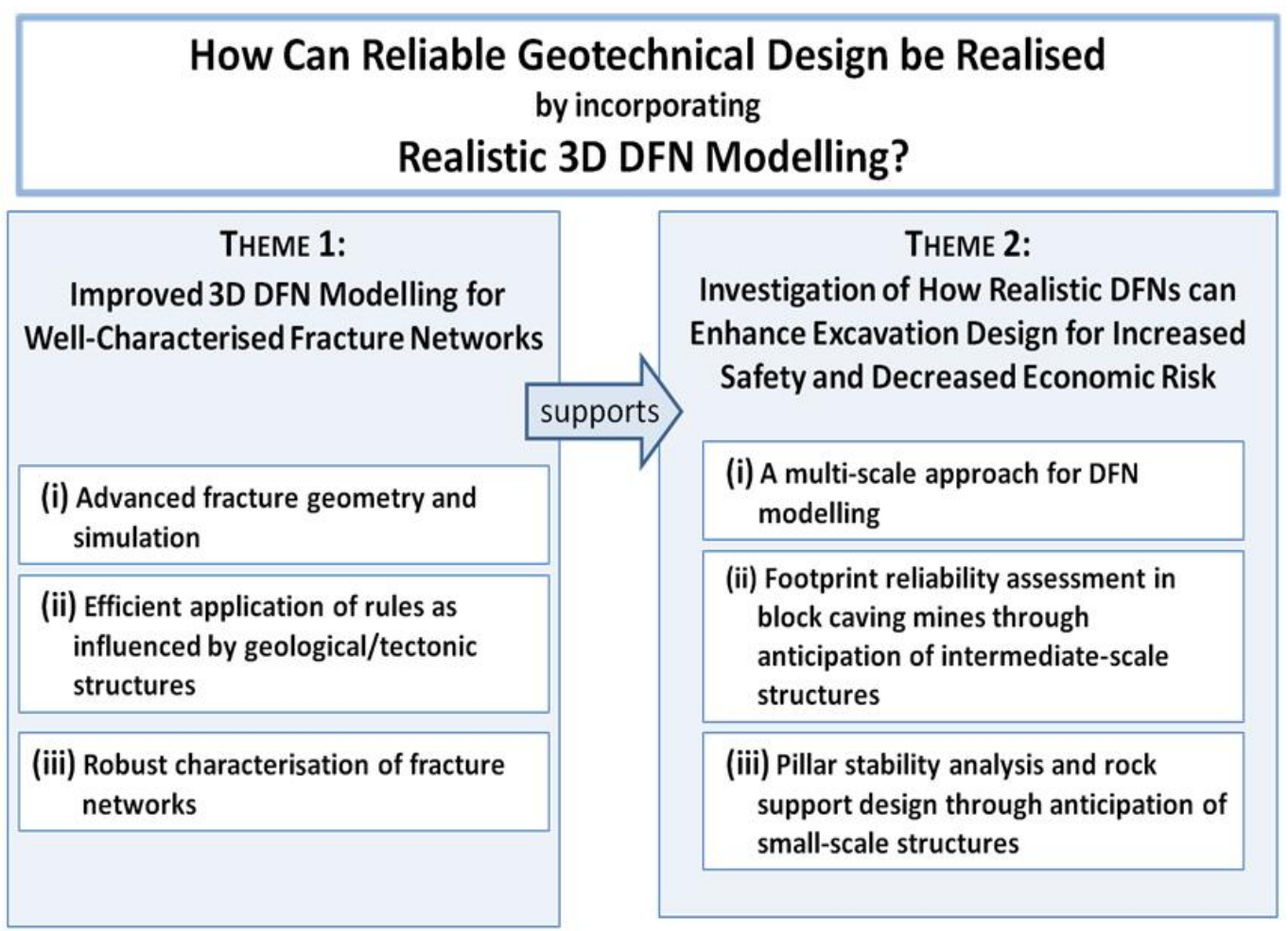

Figure 4 Suggested future research approach (after Cai \& Fava 2014)

One major difficulty in numerical simulations of fractured rock masses is the co-existence of fractures at different scales. A computationally feasible regional-scale DFN model cannot consider the smaller fractures which may be of interest for a design problem at a smaller scale. Hence, we need to reach a reasonable compromise between accuracy and efficiency in DFN modelling so that a model becomes computationally feasible and at the same time can produce meaningful renderings of fracture networks for engineering design (Figure 5). As part of the research to be undertaken by the MIRARCO group, this topic will be investigated and, it is hoped, once resolved, can offer a very meaningful contribution to the problem of fracture network impact on underground support performance and appropriate mine design approaches. 


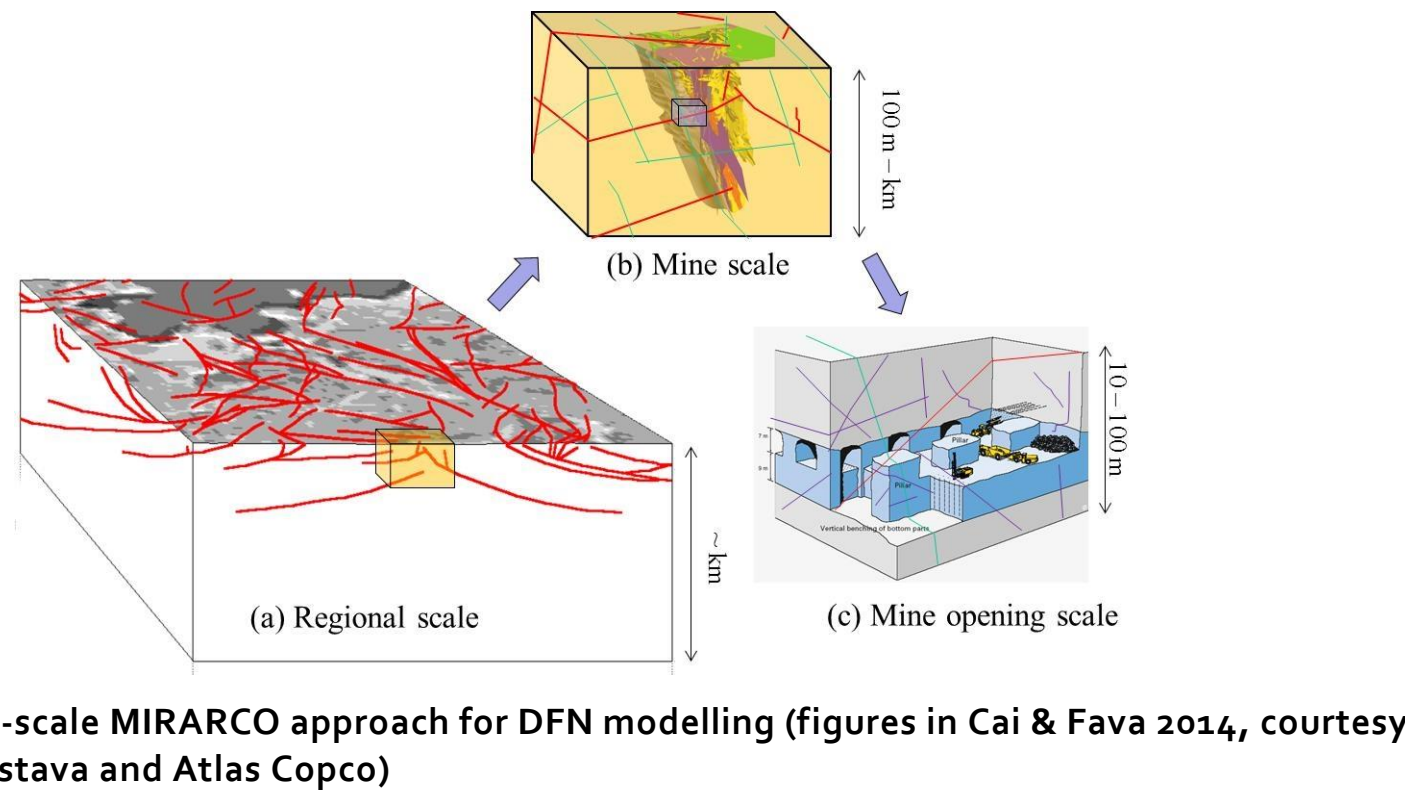

\subsection{Smart underground monitoring and integrated technologies for deep mines (SUMIT)}

CEMI's SUMIT program is now in year four of a planned five year effort looking at, among other things, the importance of rock mass characterisation and behaviour in deep underground mines in response to stress changes induced by mining. The research, it is felt, will also lead to enhanced development and production rates in mines but also to improved database management and energy optimisation in underground mines (Figure 6).

\section{- Rock mass characterisation}

- to better interpret dynamic processes, to "see into the ground", and better anticipate and minimise risks.

- Enhanced mine development

- for faster mine construction to increase economic returns.

\section{- Sustaining deep mines}

- through energy optimisation with underground environmental controls.

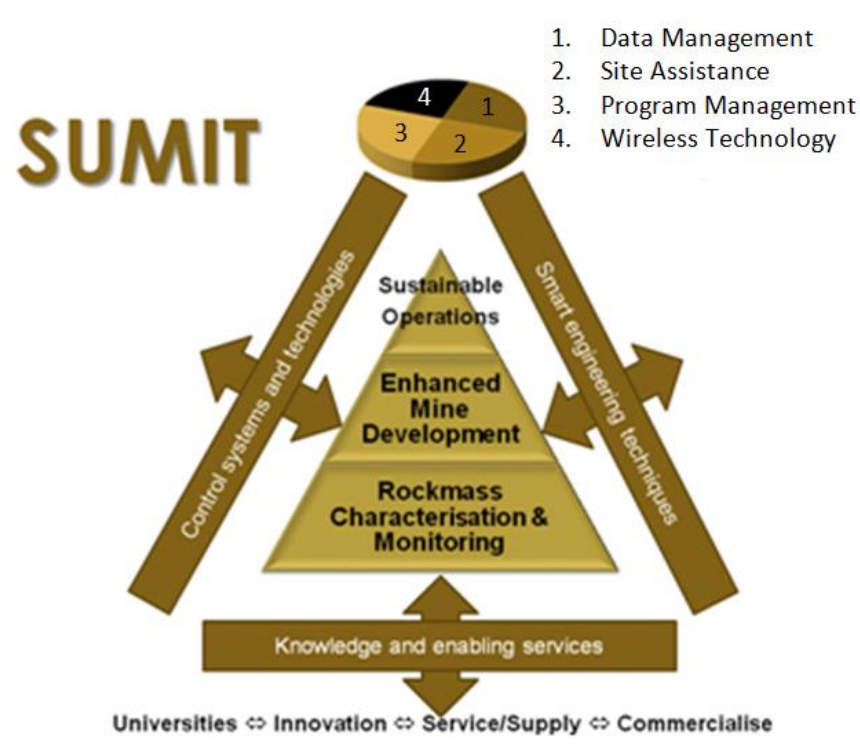

Figure 6 Major research components of the SUMIT program

\subsubsection{SUMIT geomechanics-focused work}

Regarding the geomechanics-focused work, extensive university-based research is underway by researchers at Laurentian, Queen's, Waterloo and University of Toronto in Ontario on topics ranging from geophysics and microseismicity to structural geology and mine engineering/modelling as well as change detection.

For example, at Queen's, researchers are adopting a holistic GeoRisk model system (Figure 7) with various students addressing components of this broader approach. The methodology envisions the process of 
assessing geotechnical risk in a deep underground mine as being comprised of individual hazard elements which collectively are looked at within the context of general mine project risk, including acceptability considerations, when arriving at a decision.

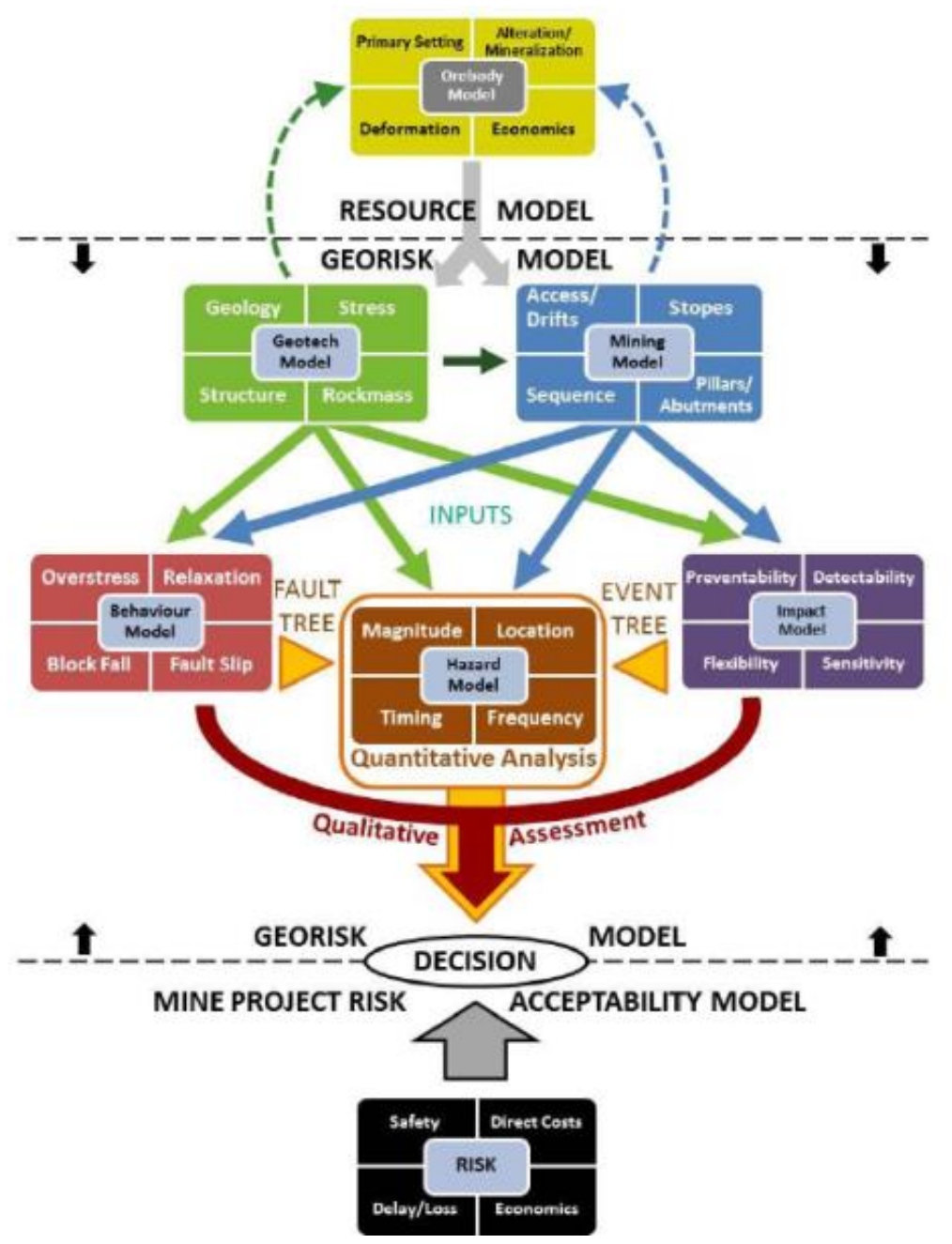

Figure 7 A GeoRisk model system approach to aspects of the SUMIT program (after Diederichs \& Hutchinson 2014)

A unifying approach is therefore being put forward by the group, comprised of elements which look at: intelligent constraints on the geological model; geotechnical characterisation through a new toolset and data collection using new instruments - all as inputs to advanced numerical modelling exercises.

Likewise, at the University of Toronto, researchers and students are seeking answers to the fundamental question: 'What should we be collectively monitoring' (to measure rock mass behaviour change in response to mining)?

Dedicated boreholes for geophysical monitoring have been installed at a test site supplied courtesy of Glencore in Sudbury. As well, development of a 3D seismic modelling methodology is underway as is the first 3D geological, petrophysical and infrastructure model of its kind for such an application.

The perennial problem of anthropomorphic noise effects on seismic signals is being also looked at and early signs are promising. Other work is focused on assessing the performance of surface- or rockbolt-mounted three component seismic sensor arrays (Figure 8). 


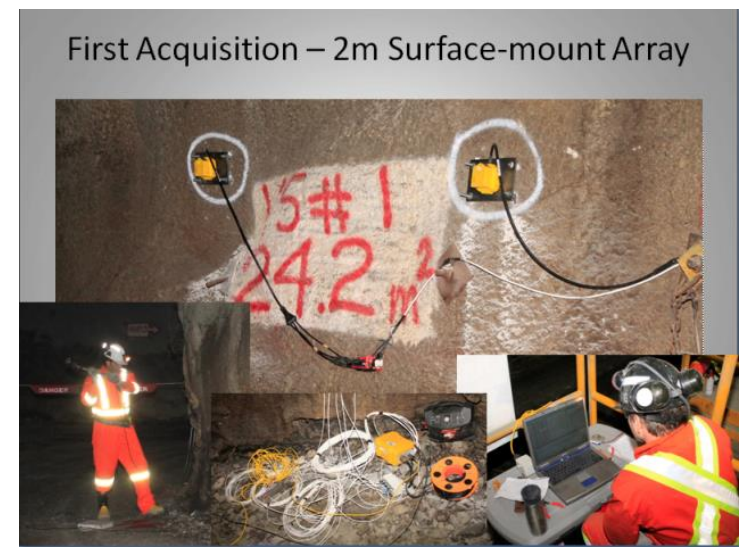

\section{Figure 8 Rockbolt-mounted seismometers and related cabling}

Laurentian University-based researchers are examining why the extent of damage in underground excavations can vary so much from place to place in response to seismically-created ground motions (Wang \& Cai (2014) based on Kaiser et al. (1996)) (Figure 9).

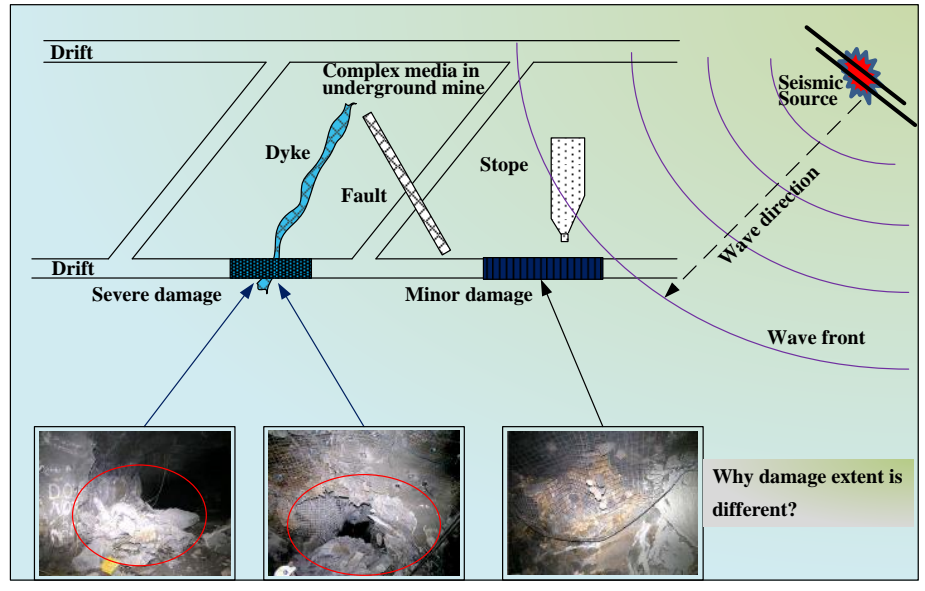

Figure 9 Varying seismicity-related damage extents in deep underground mines

Their hypothesis is that the seismic source mechanism, coupled with complex attenuation effects created by the transmission medium (rock mass) and complex excavation geometry are responsible.

The University of Waterloo group is making significant progress in examining the permeability effects created by fracture networks within a rock mass using hydraulic fracturing while at the same time evaluating in the laboratory the efficacy of a Distributed Brillouin Sensing (DBS) fibre optics strain measurement device (Figure 10). 


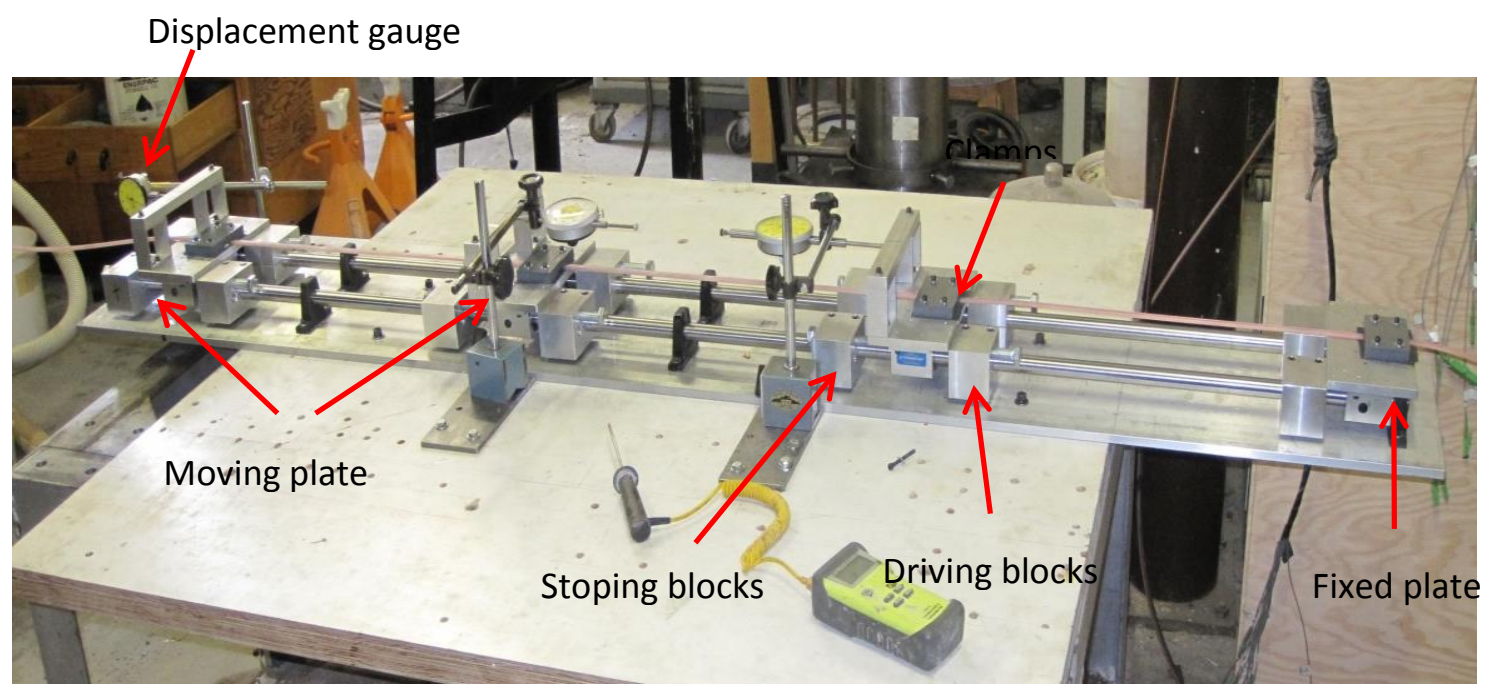

Figure 10 Laboratory setup to test the effectiveness of a distributed array fibre optics-based strain measurement system

\subsubsection{Energy optimisation-focused work (Courtesy Millar and team, Laurentian University and MIRARCO)}

The work underway in the sustainable operations area of SUMIT (Figure 11) has focused on new energy creation and existing energy optimisation approaches by the Laurentian University and MIRARCO team. Figure 12 summarises the progress to date in each of the major challenge areas identified at the project outset; expected outcomes are shown on the left while results to date are indicated in red to the right.

\section{Research challenges addressed}

- Footprint reduction through $\$ X X$ million / annum identified for energy management to reduce More on the way. production costs

- Sustaining deep mines through Deep Mine Cooling study ranks ice energy optimisation with underground environmental controls

- Value extraction from the "data OMSES case study papers: to decisions" chain stopes with $1 / 6$ of the discounted cost of refrigeration, compared to fridge plant but stay connected up to $1500 \mathrm{~km}$

- ICT applications for the mining sector; new approaches to collect, use and manage data

SankeyTrees is 'out there' as freeware; uptake has been slow.

Needs a more comprehensive user manual. OMSES 'front end' now in Development (may be a contender

LaurentianUniversity to HOMER which is a mainstream tool)

Figure 11 Energy optimisation-challenges and the work accomplished to date to address them (after Millar 2014)

Monetary savings amount so far not quantified.

The principal questions being addressed by this work include:

1. Can mine demand side energy be conserved through development of ventilation on demand technology? 
2. Can mine energy demand be reduced through the utilisation of recovered, otherwise waste heat?

3. Can technology and business agent innovations be utilised to bring about an enhanced economic environment for on-site mine energy supply?

Finally, an unexpected development under this project is the potential application of old technology hydraulic air compressors for energy production in underground mines (Figure 12).

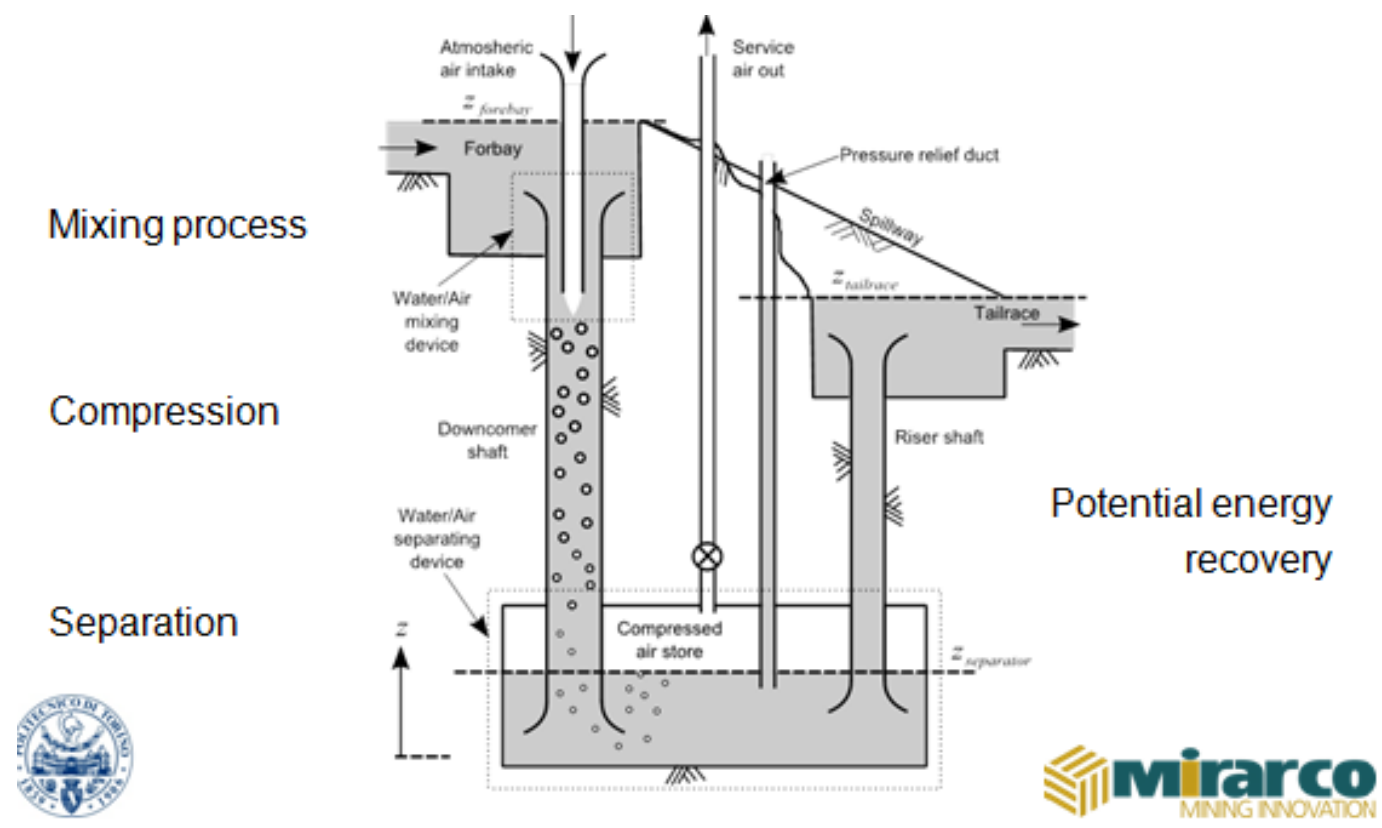

Figure 12 The HAC - the principle of the hydraulic air compressor (after Millar 2014)

\subsubsection{Database management approach for use in SUMIT (courtesy McGaughey, Mira Geoscience and Dasys, Objectivity)}

The data collection and management tasks associated with a large project like SUMIT can be onerous. Numerous researchers from different institutions and working at numerous locations (test sites) collecting data, of necessity introduces complexity.

Nevertheless, CEMI has focused from the outset on trying to construct a framework for data collection and sharing which would have the dual effect of offering a stable and usable platform for all data storage for the SUMIT Program and, importantly, which would enable a higher degree of collaboration among researchers and a greater speed of delivery of research outputs to program sponsors.

Integrator - the data storage and re-distribution platform for SUMIT (Figure 13), has been constructed by Mira Geoscience with the input of Objectivity. 


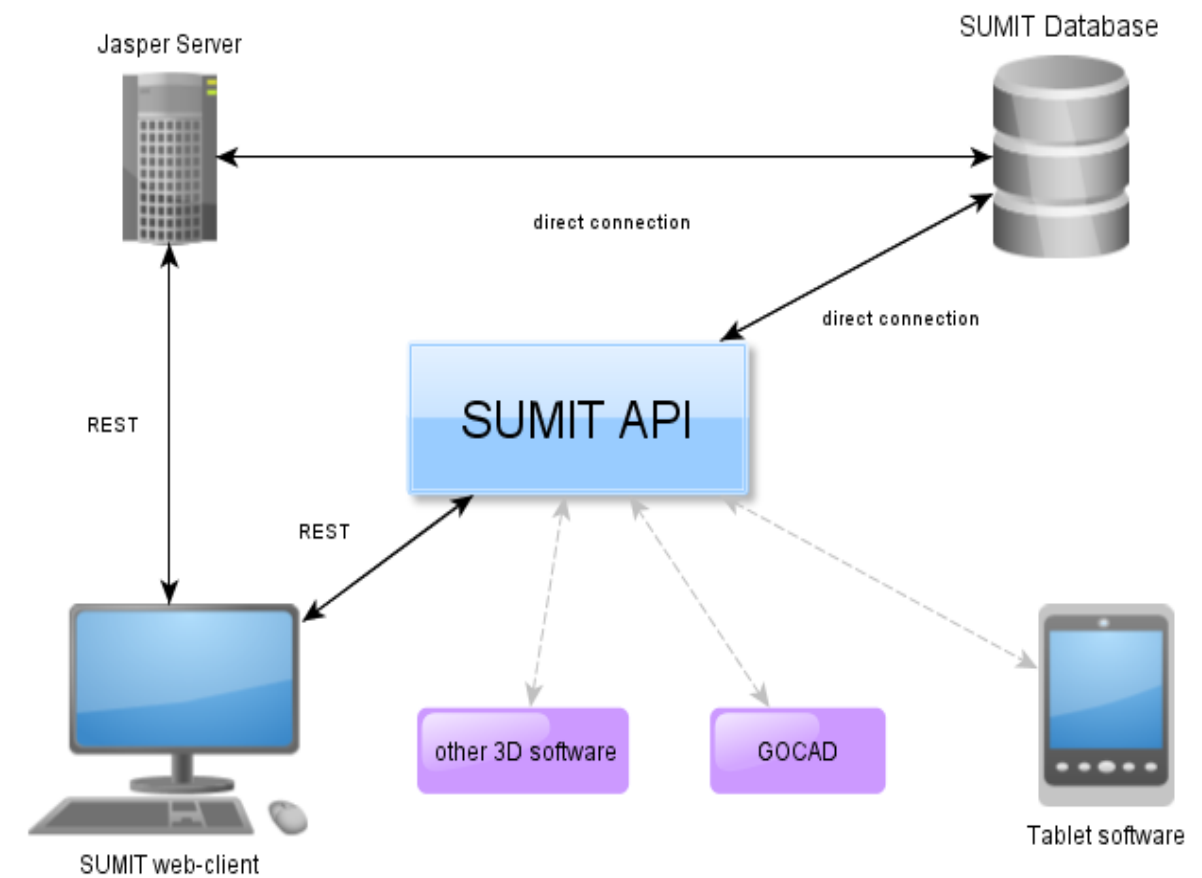

Figure 13 The system architecture for Integrator - the data management framework for SUMIT

Data are uploaded to a common data repository and shared among researchers and program sponsors alike. The vision is also that work products are uploaded and shared among researchers so that each can benefit from the other's expertise and analysis.

3D visualisation and enhanced querying capability are also being added to Integrator presently.

\subsection{Assessing rock mass response to hydraulic injection through in situ trials in deep mines}

In recent years, many mines have experimented with hydro-fracturing for stress management purposes (pre-conditioning) and considerable progress has been made. Modern technologies have advanced to the point where hydraulic fracturing with fluid and slurry injection are poised to be effectively deployed to modify rock mass behaviour and thereby potentially produce multiple benefits for stress- and energy release-management in deep mines.

In the past decade, hydro-fracturing has also been used extensively in the oil and gas industry to enhance permeability in unconventional reservoirs, but key knowledge gaps remain, especially for optimising hydro-fracture treatments and stimulated volume estimation in oil and gas reservoirs.

In 2012 it was proposed by CEMI to execute a strategic set of hydro-fracture trials in underground mines in collaboration with and for the benefit of the mining and the oil and gas industries. Such trials would provide an exceptional opportunity for inter-industry collaboration to obtain ground-truth information to advance the state-of-the-art for both industry sectors. The design of a set of strategic hydraulic fracturing trails at Newcrest Mining Limited's Cadia East Mine site in New South Wales, Australia is now complete with actual hydraulic-fracturing, initially set to commence in 2013, now scheduled to start in mid 2014, following a production-related delay at the mine.

Led by Dr Benoît Valley at ETH in Zurich and involving others from industry and academia alike, the central hypothesis of the experiment is that it is possible to promote hydraulic fracturing (propagation of new mode I fractures) and hydraulic stimulation (reactivation in shear of pre-existing fractures) by adjusting the injection parameters. Based on this hypothesis the experimental program is planned around two types of injections with different injection parameters in order to promote either hydraulic fracturing (HF) or hydraulic stimulation (HS). 
A secondary hypothesis is that in order to manage stresses and to enhance permeability, one needs to be able to permanently modify the rock mass properties. Standard hydraulic fracture placement does not generate significant effect on stresses because of the narrow zone of influence and the strength recovery after closure due to asperity locking. Two processes are hypothesised to be good candidates for efficient stress management:

1. Stress release on critically stress discontinuities by promoting shearing of these fractures through hydraulic stimulation.

2. Placement of a strength reducing agent (low friction grout) in the fracture network in order to reduce cohesive strength.

The injections will be performed using a double packer system with the injection tool having an adjustable straddle length from 2-50 $\mathrm{m}$. The system will allow for injecting up to $400 \mathrm{l} / \mathrm{min}$ and the injection sequence will include five main phases with variable straddle length and injection rates in order to promote either hydraulic fracture initiation and propagation or re-activation of pre-existing fractures. Low pressure hydraulic tests will be performed prior, between and after these main phases in order to assess permeability changes induced by the major injections.

The planned experimental layout is shown in Figures 14 and 15. Instrumentation arrays comprised of stress cells; tilt meters and an enhanced microseismic system will monitor change induced due to injection in a volume of rock some $800 \mathrm{~m}$ below surface. Further, observation holes, drilled through the volume in advance of hydraulic fracturing, then geotechnically logged and grouted, will be re-drilled and logged after completion of the injection exercise to look for any changes, specifically including newly created fractures.

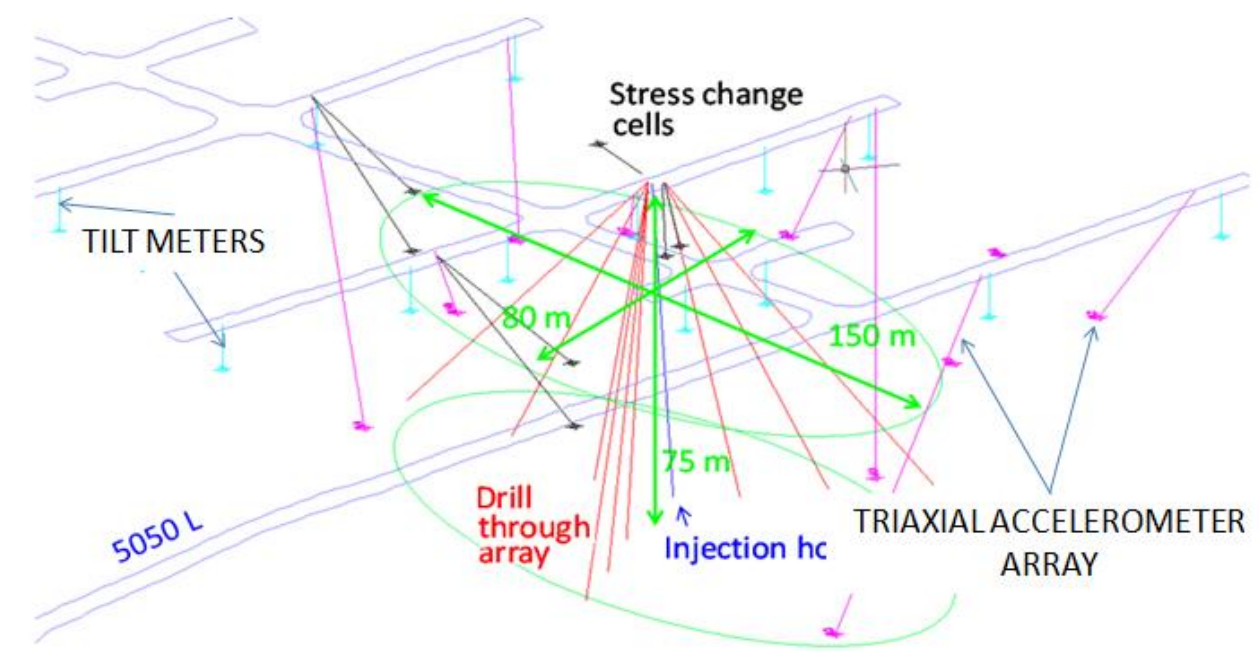

Figure 14 Outline of the proposed experimental volume and instrumentation arrays (after Valley et al. 2014) 


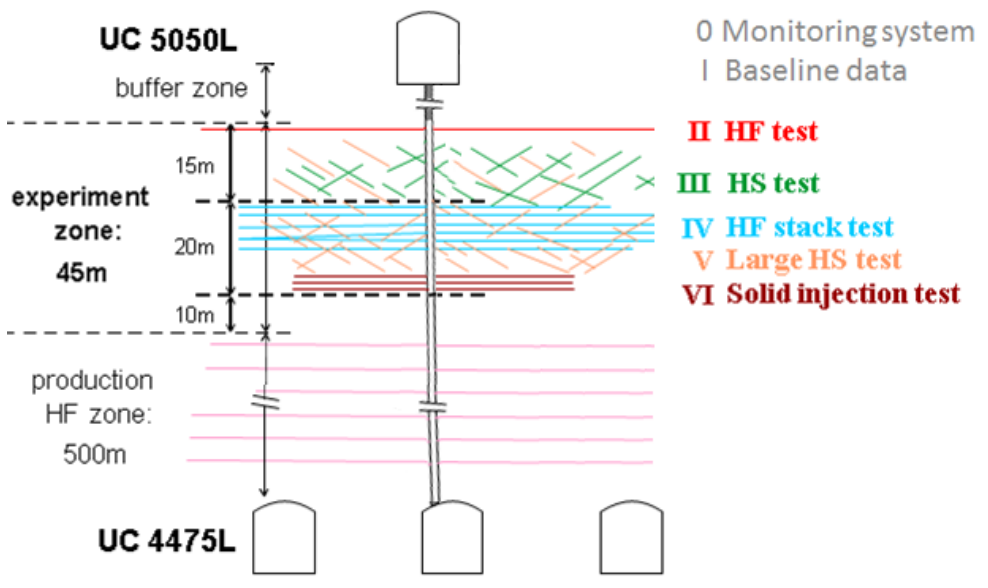

Figure $15 \mathrm{HF}$ and HS injection phases. These will be followed by a 'drill-through' to identify new fractures

\subsubsection{Related planned research objectives (after Eberhardt et al. 2014)}

The data derived from the in situ experiments will be used to address the central hypotheses by means of several research objectives (Eberhardt et al. 2014). These include those directed at better understanding the underlying mechanisms as well as those to improve our ability to monitor and model HF and HS processes. The research objectives are as follows:

1. Determine the balance between new fractures generated versus the reactivation of existing fractures for each of the different HF and HS injections. Theoretically, shear failure along pre-existing discontinuities should dominate at lower injection pressures. However, this requires that the pressure perturbation penetrates the natural fractures. In tightly confined rock masses, it is unclear how the injection strategy influences this balance.

2. Measure which permeability and stress changes induced by HF and HS are transient and which are permanent. Fracture opening is a reversible process (closure) and the net permanent effect in terms of permeability and stress is believed to be small. However, shear and dilation of fractures is irreversible and potentially has a significant effect on permanent permeability (self-propping) and stress (shear stress relief).

3. Improve the use of monitoring techniques (microseismic and tilt) to map induced fractures and volume stimulated as a function of the HF/HS injection metrics (flow rate, duration, volume). Still not fully understood is the influence of rock mass response mechanisms (tensile versus shear) on the efficiency and reliably of microseismic and tiltmeter techniques.

4. Investigate how shut-in and flow-back management influence rock mass response. Seismic events are often observed after shut-in. Rapid depressurisation (flow back) may cause fractures near the borehole to close serving to lock in pressure deeper into the rock mass.

5. Determine how far injected solids (propped volume) penetrate into a highly stressed rock mass and how it influences the stimulated volume. The use of a dilute bentonite slurry $(3 \% \mathrm{w} / \mathrm{w})$ is proposed to assess solid penetration, trace stimulated fractures and induce slip.

6. Integrate the rock mass characterisation and monitored response data to benchmark and calibrate a series of hydro-mechanically coupled discontinuum-based numerical models to improve HF and HS simulation. It is suggested that continuum-based techniques are limited as design tools, with detrimental consequences with respect to injection design. 


\section{Conclusions}

Research is both incremental and step-change in its nature. The former is achievable over a shorter timeframe and is important for keeping the scoreboard ticking over, that is, to producing tangible value within a timeframe considered useful to industry and other sponsors. The latter, of necessity, is harder and thereby more time consuming to accomplish but, if it rests on a foundation of targeted incremental approaches, can be speeded up.

CEMI has adopted this dual approach for geomechanics-focused projects within its DeepMine research and development theme with each centred on addressing fundamental issues associated with mining at depth.

However, newer energy management approaches will also be needed in these mines to reduce both costs and carbon footprints. More effective designs and operating practices will be required to enable safe and reliable operations and finally, new data management techniques will need to be developed which facilitate faster and more effective research efforts capable of being implemented sooner, with positive impacts for industry.

\section{Acknowledgement}

The contributions of the various researchers and students from multiple universities involved with this work is gratefully acknowledged as is the strong support from Vale, Glencore, Rio Tinto, Newcrest and other major mining companies, as well as various government funding agencies.

\section{References}

Cai, M \& Fava, L 2014 Improving the Reliability of Geotechnical Design by Incorporating Realistic 3D DFN Modelling, Collaborative Research and Development grant application (in preparation).

Diederichs, M \& Hutchinson, J 2014, 'SUMIT projects 2A, 2B and 4A', presentation to SUMIT project sponsor, April 15th-16th workshop at Queen's University, Kingston.

Duff, DJ, Valley, B, Milkereit, B \& McGaughey, J 2011, 'Rock mass response to deep mining induced stress- research and tools development at the CEMI, Canada', in Y Potvin (ed.), Proceedings of the Fourth International seminar on Strategic versus Tactical Approaches in Mining, Australian Centre for Geomechanics, Perth, pp. 73-84.

Eberhardt, E, Eaton, D, van der Baan, M, Schmitt, Kaiser, PK, Dusseault, M, \& Valley, B 2014, Hydraulic Fracturing versus Stimulation: Understanding Rock Mass Preconditioning and Behaviour Modification in Highly Stressed Rock through a Unique In-Situ Experiment, team submission for Natural Sciences and Engineering Research Council of Canada funding, in preparation.

Groccia, C, Cai, M \& Punkkinen, A. 2014, 'Quantifying rock mass bulking - A case study at Creighton Mine', International Journal of Rock Mechanics and Mining Sciences, in preparation.

International Mine Seismology Group 2013, S-GMAT Tool, Centre for Excellence in Mining Innovation, Sudbury, https://www.miningexcellence.ca/?p=1734

Kaiser, PK \& Cai, M 2013a, 'Critical review of design principles for rock support in burst-prone ground - time to rethink!', in Y Potvin \& B Brady, Proceedings of the Seventh International Symposium on Ground Support in Mining and Underground Construction, Australian Centre for Geomechanics, Perth, pp. 3-38.

Kaiser, PK \& Cai, M 2013b, 'Rockburst damage mechanisms and support design principles', in A Malovichko \& D Malovichko (eds), Proceedings of the 8th International Symposium on Rockbursts and Seismicity in Mines, Geophysical Survey of Russian Academy of Sciences, Obninsk, Mining Institute of Ural Branch of Russian Academy of Sciences, Perm, pp. 349-370.

Kaiser, PK, Diederichs, MS Langford, C \& Valley, B 2014, Guidelines for GeoRisk-Based Mine Design, Centre for Excellence in Mining Innovation guidelines document, CEMI, in preparation.

Kaiser, PK, Tannant, DD \& McCreath, DR 1996, Canadian Rockburst Support Handbook, Geomechanics Research Centre, Laurentian University, Sudbury.

Millar, D 2014, 'Smart Underground Monitoring and Integrated Technologies - Package 6', presentation to SUMIT project sponsor, April 15th-16th workshop at Queen's University.

Mira Geoscience 2013, GeoHazMap, Centre for Excellence in Mining Innovation, Sudbury, http://www.mirageoscience.com/data /media/target/original/gw.pdf

MIRARCO 2013, BurstSupport Tool Phase I, Centre for Excellence in Mining Innovation, Sudbury, https://www.miningexcellence.ca/?p=1760

Valley, B, Maloney, SM, Duff, D, Pesendorfer, M, Eberhardt E, Schmitt, D, Lowther, R \& Kaiser, PK 2014, 'Hydraulic injection experiment in an underground test site - Experiment layout and preliminary results', Proceedings of the 13th International Congress on Rock Mechanics, abstract, in preparation. 
Wang, X \& Cai, M, 2014, 'Numerical Modeling of Seismic Wave Propagation in Underground Mines', presentation to SUMIT project sponsor, 15-16 April workshop at Queen's University. 